\title{
MLV-VIEWER: ADVANCED GRAPHICS FOR VISUALIZATIONS IN DECISION SUPPORT SYSTEMS
}

\author{
Carlos Manuel Oliveira Alves ${ }^{1}$, Manuel Pérez Cota², María Díaz Rodríguez ${ }^{3}$ \\ and Miguel Ramón González Castro ${ }^{4}$ \\ ${ }^{1}$ Instituto Politécnico de Castelo Branco, Av. D. Pedro Álvares Cabral 12, Castelo Branco, Portugal \\ ${ }^{2}$ Dr, Universidade de Vigo, Rúa Torrecedeira 86; 36208 -Vigo, Spain \\ ${ }^{3}$ Universidade de Vigo, Rúa Torrecedeira 86; 36208 -Vigo, Spain \\ ${ }^{4}$ Dr., Universidade de Vigo, Rúa Torrecedeira 86; 36208 -Vigo, Spain
}

\begin{abstract}
Abstract. Information visualization (InfoVis) is defined as "the use of visual, interactive and visual representations supported by computer, to increase cognition". InfoVis tools and methods help us accelerate our understanding of a large amount of data. Data visualization improves understanding, especially with multidimensional data sets. Visual analysis methods allow decision makers to combine their human flexibility, creativity and knowledge with the huge storage and processing capabilities of today's computers for information about complex problems. Using advanced visual interfaces, humans can interact directly with the data analysis, adding more to their liking and need. The MLV-Viewer prototype will be described in this article.
\end{abstract}

\section{KEYWORDS}

Multi-Level Visualization on DSS, DSSM, Big Data Visualization

\section{INTRODUCTION}

In the late 1960s a new type of information system oriented to practical models, or decision support systems (DSS) or management decision systems (MDS) emerged. Peter Keen and Charles Stabe, pioneers of the DSS concept, point out that the concept evolved from theoretical studies of organizational decision making conducted at the Carnegie Institute of Technology. The origin of the DSS dates back to the beginning of the mid-20th century when the military objective was dominant. One of the oldest DSS was the SAGE (semi-automatic Ground Environment) designed to unify different images over the wide area and used in the cold war. SAGE was the largest computer ever built. According to another approach, the first DSS can originate in LEO I (Lyons Electronic Office) in 1951.

In this article, we will introduce the theme, followed by a review of the literature Madureira, Gomes, Cunha, Pereira, Santos, and Pereira (2014) on the theme "Multi-level Visualization in Decision Support Systems", with a main focus on the state of the art and finally we will describe the prototype performed and brief conclusions and future work.

\section{LITERATURE REVIEW}

According Siddiqa, A., Niazi, Mustafa, M. F., Bokhari, H., Hussain, A., Akram, N., Shaheen, S., Ahmed, F. and Iqbal, S. (2009) and Alves, C. M. O. and Cota, M. P. (2018) DSSs provides semi-structured and unstructured decision-making problem support, usually interactive, computer-based systems to assist decision-makers using various tools (such as communication, data, document, knowledge and modeling technologies) to aid in decision-making in a variety of areas, and the main components are: decision maker; data base; models and procedures; software. 
FUMAHES, NED-2 in Modi, D., Fabregas, A. and Otero, L. (2015), AgMine in Anadiotis, G., Hatzoplaki, E., K. Tsatsakis K. and Tsitsanis, T. (2015), DISASOR in Bencsik, G., Bacsárdi, L. (2015), ViDSS in Müller, H., Reihs, R., Posch, A.E., Kremer, A., Ulrich, D. and Zatloukal, K. (2016), Ma, H., Yan, L. and Wang, T. (2011), ADSyS in Lee, H., Kang, N., Han, J., Kim, J., Kim, K. H., Kim, J. D.K. and Kim, C. Y. (2013), 16Dawood, I. and Alshawi, M. (2009), ADSyS in Ni, J., Zhang C. and Ren, L. (2009), Trase, K. and Fink, E. (2014), Wang, L., Wang, G. and Alexander, C.A. (2015), Armstrong, L.J. and Nallan, S.A. (2016), Kos, L. (2014), Cota, M. P., Rodríguez, M.D., González-Castro, M. R. and Gonçalves, R. M. M. (2018), Cota, M. P., Castro, M. R. G. and Domínguez, J. A. (2014), Cota, M. P. and Castro, M. R. G. (2012), UDSS in Pankratova, N. D. and Nedashkovskaya, N. I. (2017), DISASOR in Groumpos, P. P. (2016), VMAG in Nina, R. and Yurii, T. (2015), Imen, S., Chang, N. B., Yang, Y. J. and Golchubian, A. (2016), InVEST in Henriques, S., Antunes, M. B. B., Rodrigues, C. S. C. and Werner, C. M. L. (2016) are some examples of DSSs.

\section{A NEW APPROACH: MLV-VIEWER}

The developed prototype allows the user, in a dynamic and interactive way, to select what to view and how to visualize. It starts by selecting which database, then which table (s), and finally the column (s) and their contents. If the database does not already exist in the MySQL DBMS, you can import both the logical structure (contained in an XML Schema file) and the data (contained in an XML file). If the following are displayed: $1 \mathrm{D} ; 2 \mathrm{D} ; 2 \mathrm{D}+1$; and 3D.

\subsection{MLV-Viewer Architecture}

The developed prototype needs a MySQL server as well as a PHP server, in addition to these requirements can be used by a user with a web browser. It should also be noted that by the calculation requirement the PC must have a high processing capacity.

\subsection{Visualizations with MLV-Viewer}

After selecting the table (s), the user can choose to view the data in the format (1D) CSV, XML or Listing, or if the user chooses a 2D view, it has a "Bar" view, "Lines", "Donut", or "Pyramid". The view "Bar" uses the bars format with the image of the respective product at the base of each bar, while the quantity for each reference of each product is presented either quantitative (left scale) or qualitative (image size).

So far nothing new has been added to the "usually" used for data visualization. The prototype allows a set of "smart" views with the possibility for the user to decide what to view and how to view. In this context, the user can choose which fields of a table to view as well as which "part" of the column of the table shows, and if more than one "part" is chosen, the corresponding information will be displayed in a "paired" form (see Figures 1 and 2).

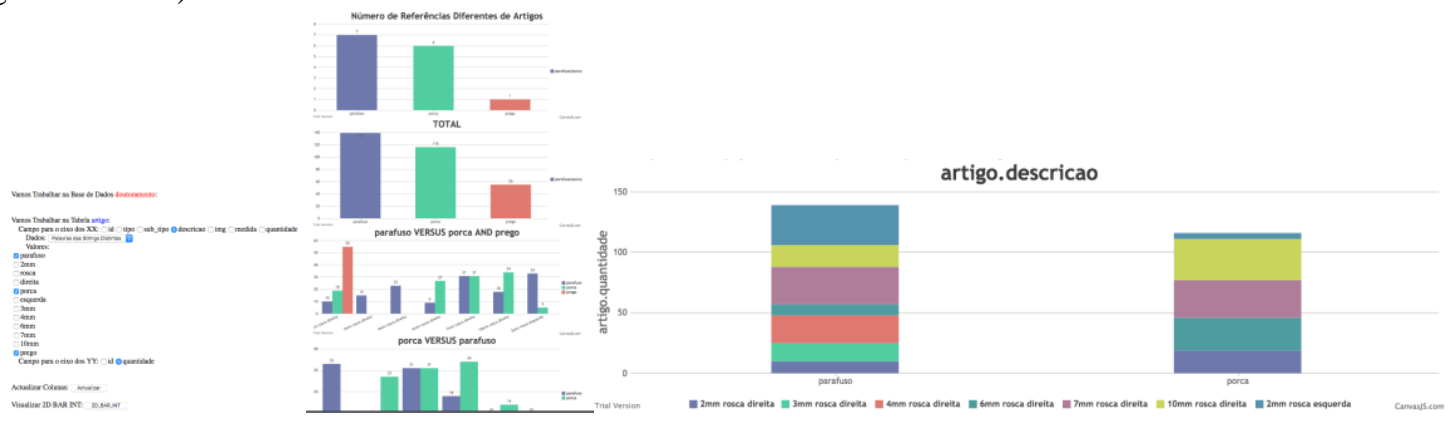

Figure 1. 2D Bars "Intelligent"

Figure 2. 2D View Stacked "Intelligent" 
It should be noted that in the following figures, classified as $2 \mathrm{D}+1$, the dimension of bubbles (Figure 3 ) reflects the dimension " $+1 "$, as well as the size of the images (Figure 4).

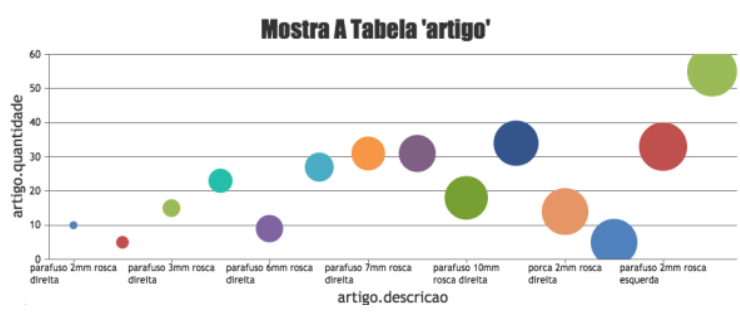

Figure 3. 2D View Bubble "Intelligent"

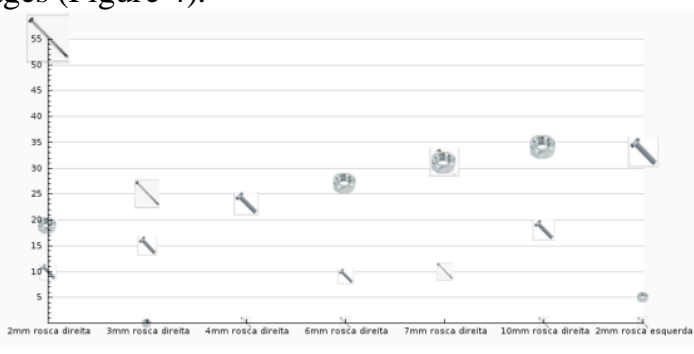

Figure 4. 2D View Line "Intelligent" with image

In Figures 5 ("Points"), 6 ("Stacked"), 7 ("Line") and 8 ("Bars") 3D visualizations are presented that allow the user to visualize interactive $3 \mathrm{D}$ (enabling, viewing angle change rotation).

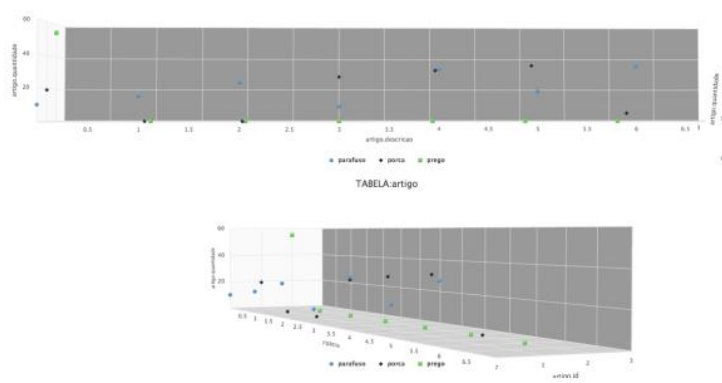

Figure 5. 3D View "Points"

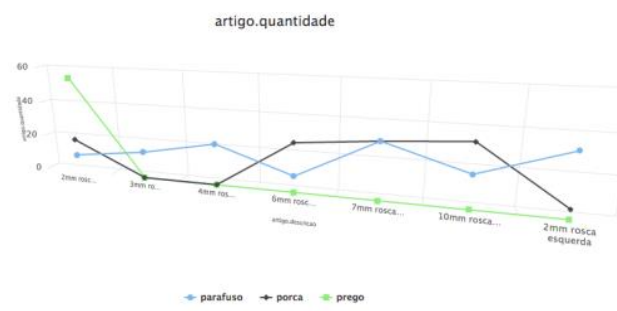

Figure 7. 3D View "Line"

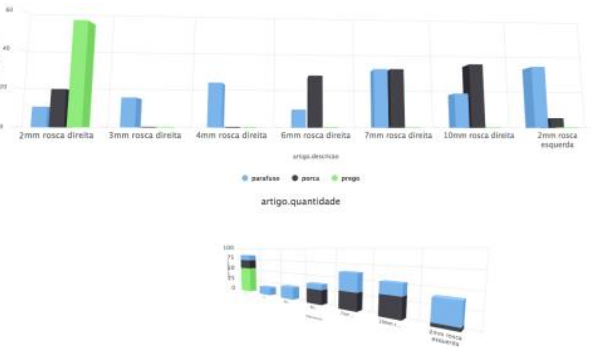

Figure 6.3D View "Stacked"

artigo.quantidade

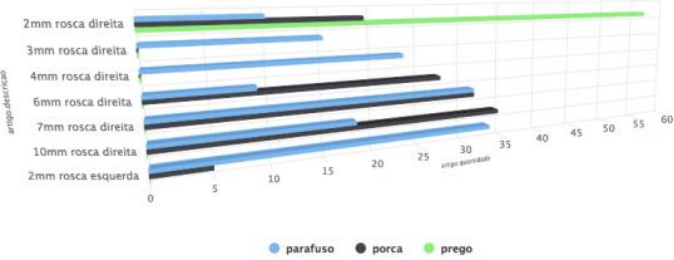

Figure 8. 3D View “horizontal Bars"

At this stage of the implementation of this prototype the objective was to allow the user, regardless of their competencies and privileges within the company, to visualize in the way that they would like the data they select.

\section{CONCLUSION AND FUTURE WORK}

All alike, all different. More, even "inside" the same individual we have differences (if the reader has doubts try to visualize the same scenario with one eye at a time). The whole computer system must be prepared to respond as widely as possible to all these vicissitudes of the most varied users. It's not easy, of course not. It is so important to allow a user to choose what to view so much, or more, to let them choose how to view those same data. A wrong choice of display type may inhibit obtaining the desired information.

The development of a software tool to support the design of the user interface of a DSS is not enough by itself, and should as far as possible meet the specifics of each user. For example, while the information may be displayed graphically, users may not be able to understand everything that is being displayed, or they may 
be overloaded with too much data to be displayed on the monitor. As we know, in any system we have input and output data, however the output / presentation of data to the user through a set of symbols is more easily understood by the user. A good system, therefore, should support users in finding meaningful information, Kos, L. (2014), in a simple way, which system should be user friendly and customizable, also suggesting the best visualization to obtain this information.

The visualization of information contained in the data through graphics or images is a developing technology transforming traditional methods of observation and analysis of relational data tables so that people can discover relationships and structure in a more intuitive way. Thus, hidden information can be easily discovered in Xin Yan, X., Qiao, M., Li, J., Simpson, T. W., Stump, G. M. and Zhang, X. (2012). A DSS visualization tool can be very important and advantageous, in Ye, X., Dai, Z., Qiu, J., \& Fang, F. (2008), in decision making, supporting managers and leaders to reach the right decision as well as ensuring business continuity and, most importantly, ensuring customer satisfaction. It is also important that the choice of DSS is correct from the outset to reduce time and cost in making the right decisions and quality. As much as possible, DSS should be easy, simple, effective and customizable. Data visualization and hence information play a key role in decision making supported by decision support systems, but we believe the challenges are still in the beginning.

With the MLV-Viewer it was intended to implement a dynamic, interactive system in which the user can choose the best way to visualize the data.

As future work is intended to make this prototype in an application advise the user on a set of views that are more recommended / advised for the branch of activity in question (but if you want, others may be chosen). On the other hand, it is intended that there are users with different profiles, and consequently with different levels of data access, which will be visualized with 3D images, following the construction of a query dynamically and with interpolation of the missing data, as well as conduct tests with data from various business areas.

\section{REFERENCES}

Alves, C. M. O. \& Cota, M. P. (2018). Multi-level visualization in decision support systems: Literature review, 201813 th Iberian Conference on Information Systems and Technologies (CISTI).

Anadiotis, G., Hatzoplaki, E., K. Tsatsakis K. \& Tsitsanis, T. (2015). A Data Model for Energy Decision Support Systems for Smart Cities - The Case of BESOS Common Information Model.

Armstrong, L.J. \& Nallan, S.A. (2016). Agricultural Decision Support Framework for Visualization and Prediction of Western Australian Crop Production, 2016 3rd International Conference on Computing for Sustainable Global Development (INDIACom).

Bencsik, G. \& Bacsárdi, L. (2015). Towards to decision support generalization: the Universal Decision Support System Concept, 2015 IEEE 19th International Conference on Intelligent Engineering Systems (INES).

Cota, M. P. \& Castro, M. R. G. (2012). Problems with the use of 3D environments in DCS: New model of visualization in operation displays, 7th Iberian Conference on Information Systems and Technologies (CISTI 2012).

Cota, M. P., Castro, M. R. G. \& Domínguez, J. A. (2014). Importance of visualization usage in enterprise decision making environements, 2014 9th Iberian Conference on Information Systems and Technologies (CISTI).

Cota, M.P., Rodríguez, M.D., González-Castro, M. R. \& Gonçalves, R. M. M. (2018). Massive Data Visualization Analysis, 2018 13th Iberian Conference on Information Systems and Technologies (CISTI).

Dawood, I. \& Alshawi, M. (2009). Decision Support Systems (DSS) Model for the Housing Industry, 2009 Second International Conference on Developments in eSystems Engineering.

Groumpos, P. P. (2016). Conceptual modeling and decision making support systems for complex dynamical systems: A critical overview, 2016 ELEKTRO.

Henriques, S., Antunes, M. B. B., Rodrigues, C. S. C. \& Werner, C. M. L. (2016). Supporting System Modeling Learning Using Gestures for Visualization Control as Method of Immersion, 2016 XVIII Symposium on Virtual and Augmented Reality.

Imen, S., Chang, N. B., Yang, Y. J. \& Golchubian, A. (2016). Developing a Model-Based Drinking Water Decision Support System Featuring Remote Sensing and Fast Learning Techniques, IEEE Systems Journal.

Kos, L. (2014). Visualization Support for Code Development in EUROfusion Integrated Modelling, MIPRO 2014. 
Lee, H., Kang, N., Han, J., Kim, J., Kim, K. H., Kim, J. D.K. \& Kim, C. Y. (2013). Interactive Manipulation and Visualization of a Deformable 3D Organ Model for Medical Diagnostic Support, The 10th Annual IEEE CCNC Conference- 3D Imaging \& Processing \& Communication and Display Track.

Ma, H., Yan, L. \& Wang, T. (2011). Dynamic Model for Enterprise Human Resources Decision SupportSystem, 2011 3rd International Workshop on Intelligent Systems and Applications.

Madureira, A., Gomes, S., Cunha, B., Pereira, J.P., Santos, J.M., \& Pereira, I. (2014). Prototype of an Adaptive Decision Support System for Interactive Scheduling with MetaCognition and User Modeling Experience, 2014 Sixth World Congress on Nature and Biologically Inspired Computing (NaBIC 2014)

Modi, D., Fabregas, A. \& Otero, L. (2015). Requirements and decision model for a taxiway route support system, 2015 Annual IEEE Systems Conference (SysCon) Proceedings.

Müller, H., Reihs, R., Posch, A.E., Kremer, A., Ulrich, D. \& Zatloukal, K. (2016). Data Driven GUI Design and Visualization for a NGS based Clinical Decision Support System, 2016 20th International Conference Information Visualisation.

Ni, J., Zhang C. \& Ren, L. (2009). An Intelligent Decision Support System of Lake Water Pollution Control Based on Multi-agent Model, 2009 International Conference on Computational Intelligence and Security.

Nina, R. \& Yurii, T. (2015). Simulation Model of the Decision-Making Support for Human-Machine Systems Operators, 2015 IEEE Seventh International Conference on Intelligent Computing and Information Systems (ICICIS'15).

Pankratova, N. D. \& Nedashkovskaya, N. I. (2017). A Decision Support System for Evaluation of Decision Alternatives on Basis of a Network Criteria Model , 2017 IEEE First Ukraine Conference on Electrical and Computer Engineering (UKRCON).

Siddiqa, A., Mustafa, F., M. F., Bokhari, H., Hussain, A., Akram, N., Shaheen, S., Ahmed, F. \& Iqbal, S. (2009). A new hybrid agent-based modeling \& simulation decision support system for breast cancer data analysis, 2009 International Conference on Information and Communication Technologies.

Sugiarto Hartono; Evaristus Didik Madyatmadja, "Decision support system model to determine contribution of own source revenue towards regional government", 2016 22nd Asia-Pacific Conference on Communications (APCC), 2016.

Tieming Liu, Qinyue Pan, Javier Sanchez, Shuzhen Sun, Ning Wang, and Hongbo Yu: Prototype Decision Support System for Black Ice Detection and Road Closure Control, IEEE Intelligent transportation systems magazine,2017

Trase, K. \& Fink, E. (2014). A Model-Driven Visualization Tool for Use with Model Based Systems Engineering Projects, 2014 IEEE Aerospace Conference.

Wang, L., Wang, G. \& Alexander, C.A. (2015). Big data and visualization: Methods, challenges and technology progress. http://pubs.sciepub.com/dt/1/1/7/.

Xin Yan, X., Qiao, M., Li, J., Simpson, T. W., Stump, G. M. \& Zhang, X. (2012). A Work-Centered Visual Analytics Model to Support Engineering Design with Interactive Visualization and Data-Mining, 2012 45th Hawaii International Conference on System Sciences.

Ye, X., Dai, Z., Qiu, J., \& Fang, F. (2008). A Metadata-Based Flexible Function Model of Decision Support Systemfor Emergency Management, 2008 4th International Conference on Wireless Communications, Networking and Mobile Computing, 2008 